\title{
The kinetics of the molybdate-catalysed epimerization of D- glucose and D-mannose in aqueous solutions
}

\section{Citation for published version (APA):}

Cybulski, A., Kuster, B. F. M., \& Marin, G. B. M. M. (1991). The kinetics of the molybdate-catalysed epimerization of D-glucose and D-mannose in aqueous solutions. Journal of Molecular Catalysis, 68(1), 87-103. https://doi.org/10.1016/0304-5102(91)80063-9

DOI:

10.1016/0304-5102(91)80063-9

Document status and date:

Published: 01/01/1991

\section{Document Version:}

Publisher's PDF, also known as Version of Record (includes final page, issue and volume numbers)

\section{Please check the document version of this publication:}

- A submitted manuscript is the version of the article upon submission and before peer-review. There can be important differences between the submitted version and the official published version of record. People interested in the research are advised to contact the author for the final version of the publication, or visit the $\mathrm{DOI}$ to the publisher's website.

- The final author version and the galley proof are versions of the publication after peer review.

- The final published version features the final layout of the paper including the volume, issue and page numbers.

Link to publication

\section{General rights}

Copyright and moral rights for the publications made accessible in the public portal are retained by the authors and/or other copyright owners and it is a condition of accessing publications that users recognise and abide by the legal requirements associated with these rights.

- Users may download and print one copy of any publication from the public portal for the purpose of private study or research.

- You may not further distribute the material or use it for any profit-making activity or commercial gain

- You may freely distribute the URL identifying the publication in the public portal.

If the publication is distributed under the terms of Article 25fa of the Dutch Copyright Act, indicated by the "Taverne" license above, please follow below link for the End User Agreement:

www.tue.nl/taverne

Take down policy

If you believe that this document breaches copyright please contact us at:

openaccess@tue.nl

providing details and we will investigate your claim. 


\title{
The kinetics of the molybdate-catalysed epimerization of D-glucose and D-mannose in aqueous solutions
}

\author{
A. Cybulski*, B. F. M. Kuster and G. B. Marin** \\ Technische Universiteit Eindhoven, Laboratorium voor Chemische Technologie, P.O. \\ Box 513, 5600 MB Eindhoven (The Netherlands)
}

(Received October 20, 1990; accepted November 9, 1990)

\begin{abstract}
The kinetics of the molybdate-catalyzed epimerization of D-glucose and D-mannose in aqueous solutions have been investigated. Batch experiments were carried out at initial sugar concentrations from 0.3 to $3 \mathrm{kmol} \mathrm{m}^{-3}$, molybdenum concentrations from 0.3 to $40 \mathrm{~mol} \mathrm{~m}^{-3}$, temperatures from 330 to $363 \mathrm{~K}$ and $\mathrm{pHs}$ from 1.9 to 3.1. Titrations of sugar/molybdate solutions with $\mathrm{HCl}$ could be described by the formation of dimolybdate complexes. The complexation and ionization equilibria are such that free molybdates can be neglected. The epimerization of D-glucose is faster than that of D-mannose. The rate of epimerization shows a maximum at a $\mathrm{pH}$ of 2.5 .

The kinetic observations are explained by a reaction sequence with a rate-determining step involving molybdate complexes of D-glucose and D-mannose as reactive intermediates and with the protonation or deprotonation of these intermediates leading to less active complexes.
\end{abstract}

\section{Introduction}

D-Mannitol can be produced by the hydrogenation of D-glucose/D-fructose solutions and subsequent separation of the desired product from the reaction mixture. An alternative route for D-mannitol manufacture consists of the catalytic epimerization of D-glucose to D-mannose, the hydrogenation of Dmannose and the crystallization of D-mannitol [1]. D-Mannose as such can also be applied in the manufacture of more sophisticated chemicals such as D-mannonic acid, D-mannaric acid and 2,6-anhydro-D-mannopyranose.

There have been extensive studies [2-11] on the epimerization of monosaccharides catalysed by molybdic compounds in aqueous media, beginning with those of Bilik and coworkers [2-8]. It has been found that the rate of reaction is highest at a $\mathrm{pH}$ from 2.5 to 3.5. Moreover, the conversion of D-glucose to D-mannose is reported to be much faster than the reverse reaction $[4,9]$.

So far, kinetic data on the epimerization have been mostly analysed in terms of first order kinetics with respect to the monosaccharide $[4,8,9$,

*Present address: Institute of Pharmaceutical Industry, Warsaw, Poland.

**Author to whom correspondence should be addressed. 
10]. The first order coefficients were found [8] to be dependent on conversion, however. The only exception is the work of Sankovic et al. [12] where kinetic data were interpreted in terms of Michaelis-Menten kinetics. Moreover, neither the influence of $\mathrm{pH}$ nor of catalyst concentration on the rate of the epimerization has been accounted for to date.

An extensive investigation of the kinetics of the molybdate-catalysed epimerization of aqueous D-glucose/D-mannose solutions is reported in the present paper. The objective of the kinetic study was to develop a rate equation allowing prediction of conversions for various process conditions and to obtain further insight into the reaction sequence.

\section{Experimental}

\section{Titration}

Solutions containing D-glucose or D-mannose and $\mathrm{Na}_{2} \mathrm{MoO}_{4}$ were titrated with $1 \mathrm{~N} \mathrm{HCl}$. The $\mathrm{pH}$ values were recorded with a potentiometer (Radiometer Titrigraph TTT80) after equilibration. The titration conditions are summarized in Table 1. In total, 402 experimental data with D-glucose and 254 with Dmannose were regressed at ambient temperature.

\section{Batch epimerization}

A glass reactor of $350 \mathrm{~cm}^{3}$ was equipped with a stirrer, a reflux condenser, a feed vessel of $100 \mathrm{~cm}^{3}$, a pH-electrode and a thermometer. The reactor and the feed vessel were jacketted and the temperature was controlled within $0.2 \mathrm{~K}$ by water circulation.

Each batch experiment was started by adding an ammonium heptamolybdate solution from the supply vessel to the sugar solution in the reactor, both solutions being at reaction temperature. The use of other molybdate sources such as combinations of $\mathrm{HCl}$ or $\mathrm{H}_{2} \mathrm{SO}_{4}$ and $\mathrm{MoO}_{3}$ or $\mathrm{Na}_{2} \mathrm{MoO}_{4}$ did not result in different kinetic behaviour. The $\mathrm{pH}$ was set by adding an appropriate amount of $\mathrm{HCl}$ to the sugar solution. For each experimental run, 15 to 20 samples were withdrawn at specific times, neutralized with a $\mathrm{NaHCO}_{3}$ solution, stored in the refrigerator at $277 \mathrm{~K}$ and analyzed by HPLC.

TABLE 1

Experimental conditions

\begin{tabular}{llll}
\hline Parameter & Titration & $\begin{array}{l}\text { Batch } \\
\text { epimerization }\end{array}$ & $\begin{array}{l}\text { Continuous } \\
\text { epimerization }\end{array}$ \\
\hline$[\mathrm{G}]_{\mathrm{o}}\left(\mathrm{kmol} \mathrm{m}^{-3}\right)$ & $0.1-4.1$ & $0.6-3.0$ & 1.2 \\
{$[\mathrm{M}]_{\mathrm{o}}\left(\mathrm{kmol} \mathrm{m}^{-3}\right)$} & $0.1-1.3$ & $0.3-1.2$ & - \\
$\left.\mathrm{Mo}(\mathrm{mol} \mathrm{m})^{-3}\right)$ & $20-70$ & $0.3-40$ & 10 \\
$\mathrm{pH}$ & $1.5-7.6$ & $1.9-3.2$ & $2.2-3.1$ \\
$T(\mathrm{~K})$ & $298-343$ & $330-363$ & $325-386$ \\
\hline
\end{tabular}


The monohydrate of $\alpha$-D-glucose was used as feedstock for 79 runs, and 25 runs were performed with $\alpha$-D-mannose as feedstock. A total of 1582 experimental data were regressed. The range of reaction conditions is listed in Table 1. Batch times amounted up to $400 \mathrm{~h}$.

\section{Continuous flow epimerization}

The continuous flow experiments were carried out in a glass, jacketted reactor containing $160 \mathrm{~cm}^{3}$ of liquid, equipped with a stirrer, reflux condenser and an additional electrical heater. Thermostatted water was circulated through the jacket. The temperature inside the reactor was maintained constant within $0.2 \mathrm{~K}$. The solutions of $\left(\mathrm{NH}_{4}\right)_{6} \mathrm{Mo}_{7} \mathrm{O}_{24}$ and sugar were continuously fed to the reactor by piston pumps. The volumetric feed flow rate ranged from 0.022 to $0.070 \mathrm{~cm}^{3} \mathrm{~s}^{-1}$. The $\mathrm{pH}$ of the solution was measured at the outlet and appropriately adjusted by acidifying the molybdate feed solution with HCl.

Steady-state conditions were reached after $10 \mathrm{~h}$ only. After this period, 6 to 10 samples were taken over a period of 3 to $5 \mathrm{~h}$. In total 16 runs were performed. Table 1 shows the range of reaction conditions.

\section{Analysis}

Samples were diluted 10- to 20-fold with water to obtain a concentration of 60 to $120 \mathrm{~mol} \mathrm{~m}^{-3}$. Calibration samples were made up from standard D-glucose and D-mannose solutions with compositions covering the experimental conversion range: $D$-glucose/D-mannose ratios from $100 / 0$ or $0 / 100$ to $65 / 35$.

The samples of $10 \mu \mathrm{l}$ were analyzed by HPLC. The column, with a length of $25 \mathrm{~cm}$ and a diameter of $4.6 \mathrm{~mm}$, was packed with BC-X8- $\mathrm{H}^{+}$ resin and kept at $338 \mathrm{~K}$. The eluent consisted of $0.005 \mathrm{M} \mathrm{H}_{2} \mathrm{SO}_{4}$ at a flow rate of $0.2 \mathrm{~cm}^{3} \mathrm{~min}^{-1}$. The detection was based on refraction and occurred at $313 \mathrm{~K}$. The detector signal was integrated digitally. No side products were detected.

Conversion and reaction rate

The conversion was calculated from:

$X=\frac{[G]_{0}-[G]}{[G]_{0}+[M]_{0}}=\frac{[M]-[M]_{0}}{[G]_{0}+[M]_{0}}$

neglecting density changes. The analytical procedure led to an absolute error below $1 \%$ for the conversion.

As the selectivity for epimerization amounted to $100 \%$, the epimerization rate was obtained directly from the mass balance for D-glucose or D-mannose. The corresponding continuity equation in the batch reactor is given by:

$\frac{\mathrm{d} X}{\mathrm{~d} t}=\frac{r}{\left([\mathrm{G}]_{0}+[\mathrm{M}]_{0}\right)}$

At low enough conversions the effect of conversion on the rate can be neglected, i.e. the reactor is operated differentially, and the continuity equation 
leads to:

$r_{0}=\frac{X}{t}\left([\mathrm{G}]_{0}+[\mathrm{M}]_{0}\right)$

with $r_{0}$ the initial rate of epimerisation. In the continuous flow stirred tank reactor, the continuity equation for $D$-glucose leads to:

$X=\frac{V_{\mathrm{r}} / F}{\left([\mathrm{G}]_{\mathrm{o}}+[\mathrm{M}]_{\mathrm{o}}\right)} r$

\section{Parameter estimation}

The regression of the experimental data was based on the maximumlikelihood criterion. Parameter estimates were obtained by minimization of the sum of squares of the residuals between the observed and the calculated values of the $\mathrm{pH}$ in the case of titrations and of the conversion in the case of batch epimerization. This minimization was achieved with a single-response Marquardt algorithm [13]. The mathematical models leading to calculated values consisted of algebraic equations originating from equilibrium relations in the case of titrations or from the continuity equation (2) in the case of batch epimerization.

The parameter estimates were tested for statistical significance by means of their approximate individual $t$ values. The limits on the parameter estimates shown in Tables 2 and 3 correspond to the individual $95 \%$ confidence intervals. The linear correlation between two parameter estimates is expressed by the binary correlation coefficient, defined as the ratio of the covariance to the square root of the product of the corresponding variances. The statistical significance of the global regression was expressed by means of the ratio of the mean regression sum of squares to the mean residual sum of squares, which is distributed according to $F$ [14]. A high value of the $F$ ratio corresponds to a high significance of the global regression. The adequacy of the mathematical models used for the regression was tested by an analysis of the residuals. Discrimination among rival models was based on this statistical testing, whenever it was not possible by direct observation or by physicochemical laws.

TABLE 2

Estimates for the major equilibrium constants shown in Fig. 2 by regressing the titration data with eqns. (6)-(11), $T_{\mathrm{m}}=296 \mathrm{~K}$

\begin{tabular}{lc}
\hline Parameter & Value \pm confidence limits \\
\hline $\log K_{2,2,1, \mathrm{G}}$ & $13.55 \pm 0.04$ \\
$\log K_{2,2,1, \mathrm{M}}$ & $14.56 \pm 0.03$ \\
$\mathrm{pK}_{2, \mathrm{G}}$ & $3.62 \pm 0.05$ \\
$\mathrm{pK}_{2, \mathrm{M}}$ & $3.46 \pm 0.02$ \\
\hline
\end{tabular}


TABLE 3

Parameter estimates obtained by regressing the 1582 batch reactor data with rate eqn. (16), $T_{\mathrm{m}}=348 \mathrm{~K}$.

\begin{tabular}{ll}
\hline Parameter & Value \pm confidence limits \\
\hline$\Delta S_{\mathrm{r}}^{\circ}\left(\mathrm{J} \mathrm{mol}^{-1} \mathrm{~K}^{-1}\right)$ & $1.322 \pm 0.009$ \\
$\Delta H_{\mathrm{r}}^{\circ}\left(\mathrm{kJ} \mathrm{mol}^{-1}\right)$ & $3.47 \pm 1.09$ \\
$A_{\mathrm{o}}\left(10^{+17} \mathrm{~s}^{-1}\right)$ & $6.65 \pm 0.52$ \\
$\left.E_{\mathrm{a}}(\mathrm{kJ} \mathrm{mol})^{-1}\right)$ & $126.1 \pm 1.4$ \\
$K_{3,2,1, \mathrm{M}} / K_{3,2,1, \mathrm{G}}$ & $26.8 \pm 2.3$ \\
$\mathrm{pK}_{2, \mathrm{G}}$ & $4.11 \pm 0.30$ \\
$\mathrm{pK}_{2, \mathrm{M}}$ & $3.81 \pm 0.06$ \\
$\mathrm{pK}_{1, \mathrm{G}}$ & $1.82 \pm 0.08$ \\
$\mathrm{pK}_{1, \mathrm{M}}$ & $0.49 \pm 0.07$ \\
\hline
\end{tabular}

To facilitate the estimation of activation energies and/or heat of reaction, a re-parametrization was applied:

$k=A_{0} \exp \left(-\frac{E}{R T}\right)=A_{0}^{\prime} \exp \left[-\frac{E}{R T}\left(\frac{1}{T}-\frac{1}{T_{\mathrm{m}}}\right)\right]$

with $T_{m}$ the average temperature of the experiments.

\section{Equilibria in aqueous molybdate solutions}

It is well known [15-21] that numerous polyanions are formed from molybdic acid in aqueous solutions. Sugars, moreover, form complexes with molybdates [22-31]. The relative stability of the different species depends on the $\mathrm{pH}$, the monomolybdate and the sugar concentrations. This can be accounted for considering reactions of the type:

$p \mathrm{H}^{+}+q \mathrm{MoO}_{4}{ }^{2-}+r \mathrm{~S} \rightleftharpoons \mathrm{S}_{r} \mathrm{H}_{p-2 n} \mathrm{Mo}_{q} \mathrm{O}_{4 q-n}^{(2 q-p)-}+n \mathrm{H}_{2} \mathrm{O}$

the equilibrium coefficient of which, $K_{p, q, r}$, being the stability constant for the $\mathrm{S}_{r} \mathrm{H}_{p-2 n} \mathrm{Mo}_{q} \mathrm{O}_{q q-n}^{(2 q-p)-}$ species. For dilute solutions the following relation holds at equilibrium

$K_{p, q, r}=\frac{\left[\mathrm{S}_{r} \mathrm{H}_{p-2 n} \mathrm{Mo}_{q} \mathrm{O}_{4 q-n}^{2 q-p)-}\right]}{\left[\mathrm{H}^{+} \mathrm{P}^{p}\left[\mathrm{MoO}_{4}^{2-}\right]^{q}[\mathrm{~S}]^{r}\right.}$

For sugar-free solutions, stability constants, $K_{p, q, o}$, have been reported at room temperature for anions containing up to 36 . molybdenum atoms. Equilibrium calculations show that the hepta- and octamolybdate polyanions are the most abundant species at a $\mathrm{pH}$ and a monomolybdate concentration typical for molybdate-catalysed epimerization. At these conditions the dimolybdate concentration is at least two orders of magnitude lower. 
Less is known about the relative stabilities of polymolybdate anions complexed with sugars. Potentiometric titrations and ${ }^{95} \mathrm{Mo}$ NMR led Verchere and Chapelle [22] to the conclusion that a single molecule of D-mannose forms an anionic complex with dimolybdate in acidic solutions at room temperature. To obtain more detailed information, potentiometric titrations have been performed close to epimerization conditions, viz. Table 1. Figure 1 shows two typical titration curves at room temperature, one for D-glucose and one for D-mannose. Apparently there is a first equivalence point for both D-glucose and D-mannose at which one mole of $\mathrm{HCl}$ per mole of monomolybdate has been added. A second equivalence point seems to be reached after adding three moles of $\mathrm{HCl}$ per two moles of monomolybdate. Thus the titration curves indicate that equilibria involving $p / q$ ratios of 1 and 1.5 are important at the conditions investigated. This points to species such as $\mathrm{SMo}_{2} \mathrm{O}_{7}{ }^{2-}$ and $\mathrm{SHMo}_{2} \mathrm{O}_{7}{ }^{-}$respectively, as shown in Fig. 2. The form of the titration curves clearly does not allow an accurate estimation of stability constants such as $K_{2,2,1}$ and $K_{3,2,1}$ based on the equivalence points of a single titration. Therefore a regression of all the titration data at room temperature, i.e. for different monomolybdate and sugar concentrations, both D-glucose and D-mannose, was performed to obtain these estimates. The most significant regression was obtained by taking into account the equilibria shown in Fig. 2 , the equilibria describing the relative stabilities of the most important molybdate polyanions in sugar-free solutions, i.e. 20 equations similar to (6) with $r=0$, the Mo balance:

$$
\begin{aligned}
\mathrm{Mo}_{\mathrm{t}}= & 2\left(\left[\mathrm{SMo}_{2} \mathrm{O}_{7}{ }^{2-}\right]+\left[\mathrm{SHMo}_{2} \mathrm{O}_{7}{ }^{-}\right]+\left[\mathrm{SH}_{2} \mathrm{Mo}_{2} \mathrm{O}_{7}\right]\right) \\
& +\sum_{k} q_{k}\left[\mathrm{MoO}_{4}{ }^{2-}\right]^{q k}\left[\mathrm{H}^{+}\right]^{p_{k}} K_{p, q, o}+\left[\mathrm{MoO}_{4}{ }^{2-}\right]
\end{aligned}
$$

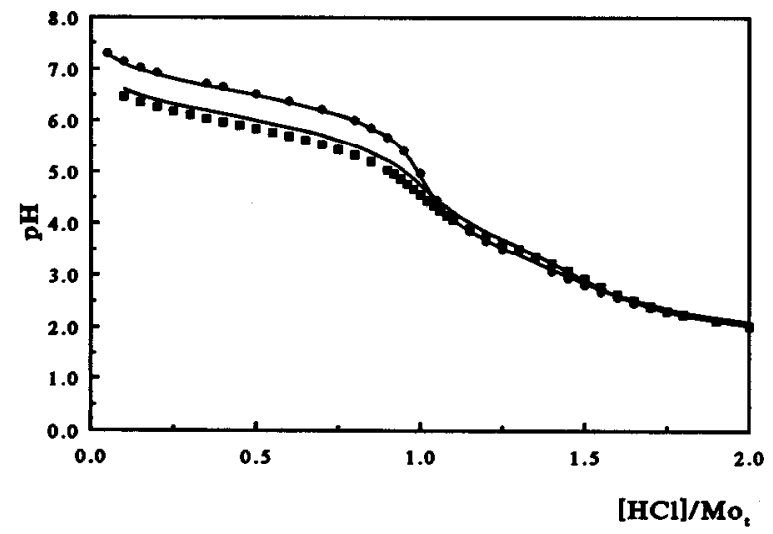

Fig. 1. Titration curves at room temperature, $[S]=1.3 \mathrm{kmol} \mathrm{m} \mathrm{m}^{-3}, \mathrm{Mo}_{\mathrm{i}}=20 \mathrm{~mol} \mathrm{~m} \mathrm{~m}^{-3}$. Points (experimental values): D-glucose ( $\square$ ), D-mannose $(\theta) .(-)$ calculated from eqns. (6)-(11) with estimates from Table 2. 
and, finally, the charge balance:

$$
\begin{aligned}
{\left[\mathrm{Na}^{+}\right]+\left[\mathrm{H}^{+}\right]=} & {\left[\mathrm{Cl}^{-}\right]+2\left[\mathrm{SMo}_{2} \mathrm{O}_{7}{ }^{2-}\right]+\left[\mathrm{SHMo}_{2} \mathrm{O}_{7}{ }^{-}\right] } \\
& +\sum_{k}\left(p_{k}-2 q_{k}\right)\left[\mathrm{H}^{+}\right]^{p_{k}}\left[\mathrm{MoO}_{4}{ }^{2-}\right]^{q k} K_{p, q, o}+2\left[\mathrm{MoO}_{4}{ }^{2-}\right]
\end{aligned}
$$

Table 2 gives the obtained estimates for the sugar complexation constants, $K_{2,2,1}$, and for the proton dissociation constant, $K_{2}$.

Note that:

$\log K_{3,2,1}=\log K_{2,2,1}+\mathrm{pK}_{2}$

As at equilibrium:

$K_{2}=\frac{\left[\mathrm{H}^{+}\right]\left[\mathrm{SMo}_{2} \mathrm{O}_{7}{ }^{2-}\right]}{\left[\mathrm{SHMo}_{2} \mathrm{O}_{7}{ }^{-}\right]}$

The estimates for the equilibria involving D-mannose agree with the values reported by Verchere and Chapelle [22]. The third equilibrium, shown in Fig. 2, must be included to describe adequately the titration curves at $\mathbf{p H}$ values lower than 3:

$K_{\mathrm{I}}=\frac{\left[\mathrm{H}^{+}\right]\left[\mathrm{SHMo}_{2} \mathrm{O}_{7}^{-}\right]}{\left[\mathrm{SH}_{2} \mathrm{Mo}_{2} \mathrm{O}_{7}\right]}$

The corresponding $\mathrm{pK}_{1}$ estimates, amounting to 0.85 for $\mathrm{D}$-glucose and 1.54 for D-mannose, are less accurate. Possibly this is caused by the decomposition of the uncharged complex into polymolybdates and sugar or by the formation of higher polymolybdate sugar complexes at these low $\mathrm{pH}$ values. The largest binary correlation coefficient amounts to 0.35 . Figure 3 shows a parity diagram for the titrations with D-mannose. The parity diagram for D-glucose is similar. Clearly, it is sufficient to consider the species and equilibria shown in Fig. 2 to describe adequately the titration experiments at room temperature. Equilibria involving hepta- or octamolybdates did not allow such a description. The obtained estimates for the equilibrium constants corresponding to Fig. 2 allow, together with the $K_{p, q, o}$ constants from the literature, calculation of the equilibrium concentrations of the free molybdates and the sugar molybdate complexes. At sugar/molybdenum ratios and $\mathrm{pH}$ values typical for the molybdate-catalysed epimerization, more than $97 \%$ of the molybdate is present

$$
\begin{aligned}
& 2 \mathrm{H}^{*}+2 \mathrm{MoO}_{4}{ }^{2-}+\mathrm{S} \& \mathrm{SMO}_{2} \mathrm{O}_{3}{ }^{3-}+\mathrm{H}_{2} \mathrm{O} \mathrm{K}_{2,2,1} \\
& \mathrm{H}^{+}+\mathrm{SMO}_{2} \mathrm{O}_{1}{ }^{2-} \quad \text { SHMo } \mathrm{O}_{1}^{-} \quad \mathbf{K}_{2}^{-1} \\
& \mathrm{H}^{*}+\mathrm{SHMo}_{2} \mathrm{O}_{1}^{-} \bigoplus \mathrm{SH}_{2} \mathrm{Mo}_{2} \mathrm{O}_{1} \quad \mathrm{x}_{1}^{-1}
\end{aligned}
$$

Fig. 2. Main species and equilibria in aqueous solutions of D-glucose or D-mannose, $S$, and molybdate. [S] 0.1-4 $\mathrm{kmol} \mathrm{m}^{-3}, \mathrm{Mo}_{\mathrm{t}} 20-70 \mathrm{~mol} \mathrm{~m}^{-3}, \mathrm{pH} \mathrm{7.7-1.5}$ and $\mathrm{T}$ 298-343 $\mathrm{K}$. 


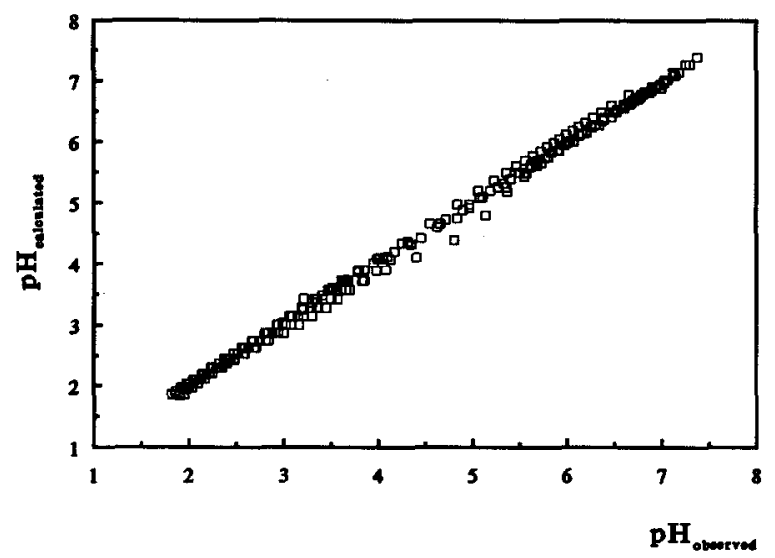

Fig. 3. Parity diagram for the titrations with D-mannose at room temperature.

in the form of the sugar complexes shown in Fig. 2. Free molybdate anions become only significant at $\mathrm{pH}$ values higher than 5 . Hence, the molybdenum balance at $\mathrm{pH}$ values lower than 5 reduces to:

$\mathrm{Mo}_{\mathrm{t}}=2\left(\left[\mathrm{SMo}_{2} \mathrm{O}_{7}{ }^{2-}\right]+\left[\mathrm{SHMo}_{2} \mathrm{O}_{7}-\right]+\left[\mathrm{SH}_{2} \mathrm{Mo}_{2} \mathrm{O}_{7}\right]\right)$

and the concentrations for the sugar complexes depend only on the total molybdenum concentration and the equilibrium constants of the protonation steps, e.g. for $\left[\mathrm{SHMo}_{2} \mathrm{O}_{7}^{-}\right]$:

$\left[\mathrm{SHMo}_{2} \mathrm{O}_{7}{ }^{-}\right]=\frac{\frac{1}{2} \mathrm{Mo}_{\mathrm{t}}}{1+\left[\mathrm{H}^{+}\right] / K_{1, \mathrm{~s}}+K_{2, \mathrm{~S}} /\left[\mathrm{H}^{+}\right]}$

It follows from eqn. (13) that $\left[\mathrm{SHMo}_{2} \mathrm{O}_{7}{ }^{-}\right]$reaches a maximum for:

$\mathrm{pH}_{\max }=\frac{1}{2}\left(\mathrm{pK}_{1, \mathrm{~s}}+\mathrm{pK}_{2, \mathrm{~s}}\right)$

Obviously, there are no maxima for $\left[\mathrm{SMo}_{2} \mathrm{O}_{7}{ }^{2-}\right]$, nor for $\left[\mathrm{SH}_{2} \mathrm{Mo}_{2} \mathrm{O}_{7}\right]$ at $\mathrm{pH}$ values lower than 5 .

Some titrations were performed at temperatures above ambient in order to investigate the temperature dependence of the equilibria shown in Fig. 2. Interference of epimerization while titrating inhibited quantification of the latter. The heat of complexation lies between 20 and $40 \mathrm{~kJ} \mathrm{~mol}^{-1}$, which is low enough to extrapolate the conclusions derived from the titrations at room temperature to typical epimerization temperatures.

\section{Kinetics of epimerization}

Influence of the reaction conditions on the initial rate of epimerization

Figure 4 shows typical conversion versus time curves obtained in the batch reactor. The rate of epimerization of D-glucose to D-mannose is much 


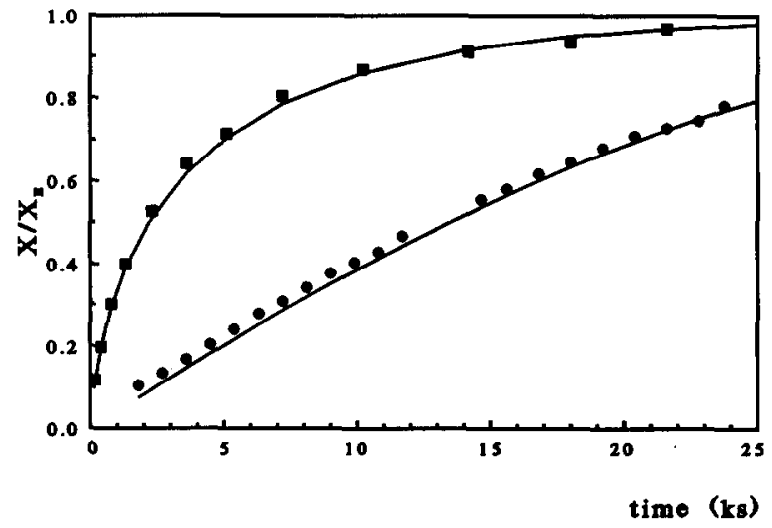

Fig. 4. $X / X_{\mathrm{I}}$ vs. time curve for D-glucose $(\mathrm{D})$ and $\mathrm{D}$-mannose $(0), 346 \mathrm{~K}, \mathrm{pH}=2.50,[\mathrm{~S}]_{\mathrm{o}}=1.2$ kmol m $\mathrm{m}^{-3}, \mathrm{Mo}_{\mathrm{t}}=10 \mathrm{~mol} \mathrm{~m} \mathrm{~m}^{-3}$, batch reactor. $(\longrightarrow$ ) Calculated from integration of eqn. (2) with rate eqn. (16) and the parameter estimates from Table 3.

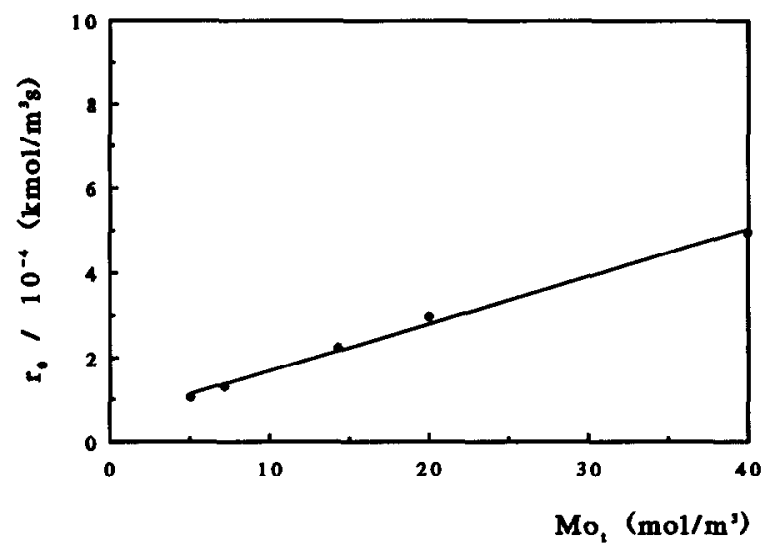

Fig. 5. Initial rate of D-glucose epimerization vs. molybdenum concentration, $248 \mathrm{~K}$, $\mathrm{pH}=2.67 \pm 0.14,[\mathrm{G}]_{\mathrm{o}}=1.2 \mathrm{kmol} \mathrm{m}^{-3}$.

higher than the rate of epimerization of D-mannose to D-glucose. Equation (3) applies to the linear part of such curves and allows calculation of the initial rates of epimerization from them.

Figure 5 shows a linear dependence of the initial rate on the molybdenum concentration. The influence of the sugar concentration is shown in Fig. 6 to be absent. Both of these observations can be explained by eqn. (13) if it is assumed that there exists a rate-determining step involving $\mathrm{SHMo}_{2} \mathrm{O}_{7}{ }^{-}$.

The influence of the $\mathrm{pH}$ on the initial rate of epimerization is shown in Fig. 7. The initial rate reaches a maximum at a $\mathrm{pH}$ of $\sim 2.5$ for both $\mathrm{D}$ glucose and $\mathrm{D}$-mannose, which is close to the values of $\mathbf{p H}_{\max }$ calculated from eqn. (14) and the estimates for $\mathrm{pK}_{1, \mathrm{~s}}$ and $\mathrm{pK}_{2, \mathrm{~s}}$ reported in the previous section. This agreement can be understood if $\mathrm{SHMo}_{2} \mathrm{O}_{7}{ }^{-}$is the only species involved in the rate-determining step of the epimerization. 


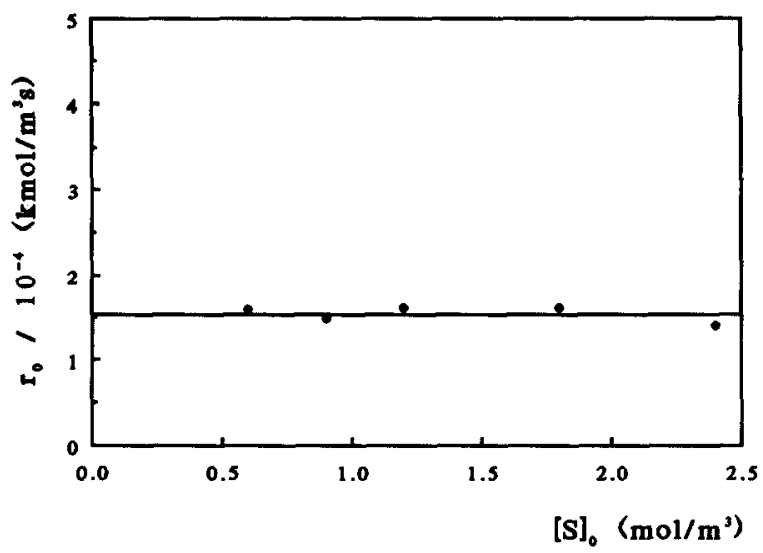

Fig. 6. Initial rate of $\mathrm{D}$-glucose epimerization vs. sugar concentration, $348 \mathrm{~K}, \mathrm{pH}=2.70 \pm 0.03$, $\mathrm{Mo}_{\mathrm{t}}=10 \mathrm{~mol} \mathrm{~m}^{-3}$.

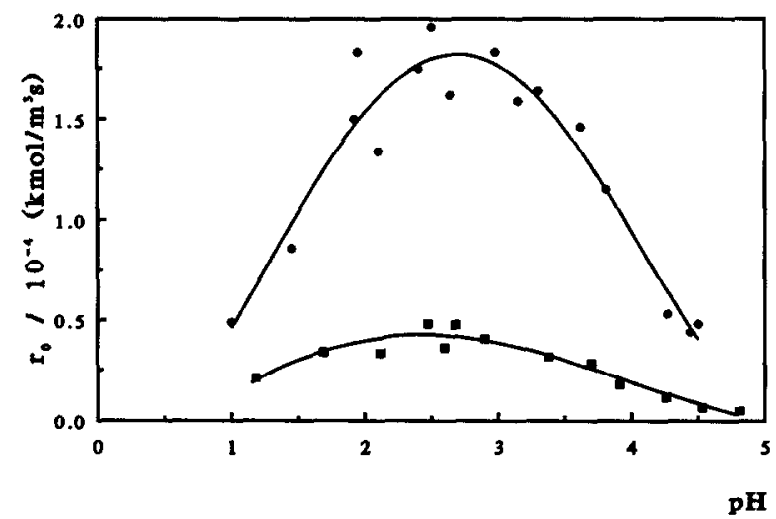

Fig. 7. Initial rate of epimerization vs. pH. D-glucose (O), D-mannose ( $\mathrm{mol} \mathrm{m} \mathrm{m}^{-3},[\mathrm{~S}]_{0}=1.2 \mathrm{kmol} \mathrm{m}^{-3}$.

$D$-Glucose and D-mannose are present in the form of $\alpha$ - and $\beta$-pyranose anomers in aqueous solutions. The so-called mutarotation from one anomer to the other occurs through the relatively unstable aldehyde form at rates which can be estimated to be at least two orders of magnitude higher than the rate of epimerization [32]. Hence, it can be expected that the initial rate of epimerization of D-glucose or D-mannose will not be affected by the initial ratio of the anomers. Replicate experiments were performed in the continuous flow stirred tank reactor set-up, viz. Table 1. One set of these experiments was performed with a feed containing mainly $\alpha$-D-glucose, another set with a feed containing mainly $\beta$-D-glucose. There was no statistically significant difference in the initial rate of epimerization between the $\alpha$-D-glucose-rich feed and $\beta$-D-glucose-rich feed. Hence, the kinetics of epimerization can be based on the combined, i.e. without distinguishing between the anomers, concentrations of D-glucose and D-mannose. 
Reaction sequence for epimerization

The observations reported in the two previous sections lead to the reaction sequence for epimerization shown in Fig. 8. It features a ratedetermining step consisting of the monomolecular transformation of a molybdate complex of glucose into a molybdate complex of mannose. These complexes are in a dynamic equilibrium with the free molybdate anion and sugar, the equilibrium being strongly towards to complexed side. The complexation equilibria shown in Fig. 8 are obviously not elementary reactions. The details of these reactions are not kinetically significant as long as the carbon skeleton rearrangement step is rate-determining. It is postulated that the complex is formed with a dimolybdate anion in analogy with the existing equilibria in the absence of epimerization, viz. Fig. 2. Finally, the $\mathrm{pH}$ dependence of the rate of epimerization requires that the complex involved in the rate-determining step can dissociate a proton and can be protonated. Hence, $\mathrm{SHMO}_{2} \mathrm{O}_{7}{ }^{-}$, which also features in the reactions describing the equilibria in the absence of epimerization, is proposed as the reaction intermediate involved in the rate-determining step.

\section{Rate equation for epimerization}

If it is assumed that the reaction sequence shown in Fig. 8 is the only significant one, the rate of epimerization follows from the application of the law of mass action on the carbon skeleton rearrangement step:

$r=k_{\mathrm{G}}\left[\mathrm{GHMo}_{2} \mathrm{O}_{7}^{-}\right]-k_{\mathrm{M}}\left[\mathrm{MHMo}_{2} \mathrm{O}_{7}^{-}\right]$

Taking into account the equilibria of the other reactions shown in Figs. 2 and 8 , eqns. (6), (10) and (11) as well as the absence of uncomplexed molybdate anions, eqns. (12) and (13), leads to a rate equation featuring only observable process variables and thermodynamic and kinetic parameters:

$$
r=\frac{\frac{1}{2} k_{\mathrm{G}} K_{3,2,1, \mathrm{G}} \mathrm{Mo}_{\mathrm{t}}([\mathrm{G}]-[\mathrm{M}] / K)}{\left(1+\left[\mathrm{H}^{+}\right] / K_{1, \mathrm{G}}+\mathrm{K}_{2, \mathrm{G}} /\left[\mathrm{H}^{+}\right]\right) K_{3,2,1, \mathrm{G}}[\mathrm{G}]+\left(1+\left[\mathrm{H}^{+}\right] / K_{1, \mathrm{M}}+K_{2, \mathrm{M}} /\left[\mathrm{H}^{+}\right]\right) K_{3,2,1, \mathrm{M}}[\mathrm{M}]}
$$

$$
\begin{aligned}
& 3 \mathrm{H}^{+}+2 \mathrm{MoO}_{4}{ }^{2-}+\mathrm{G} \bigoplus \mathrm{GHMO}_{2} \mathrm{O}_{7}^{-}+\mathrm{H}_{2} \mathrm{O} \quad \mathrm{K}_{3,2,1,6} \\
& \mathrm{GHMO}_{2} \mathrm{O}_{7}^{-} \underset{\mathrm{x}_{\mathrm{u}}}{\stackrel{\mathrm{x}_{0}}{\longrightarrow}} \mathrm{MHMO}_{2} \mathrm{O}_{7}-
\end{aligned}
$$

$$
\mathrm{H}_{2} \mathrm{O}+\mathrm{MHMO}_{2} \mathrm{O}_{7}^{-} \rightleftarrows \mathrm{M}+\mathrm{MOO}_{4}{ }^{2-}+3 \mathrm{H}^{+} \mathrm{K}_{3,2,1, \mathrm{M}}^{-1}
$$

Fig. 8. Reaction sequence for the epimerization of $D$-glucose, $G$, into $D$-mannose, $M$, in aqueous molybdate solutions. [S] $0.3-3.0 \mathrm{kmol} \mathrm{m}^{-3}, \mathrm{Mo}_{\mathrm{t}} 0.30-40 \mathrm{~mol} \mathrm{~m}^{-3}, \mathrm{pH} 1.9-3.2$ and $T$ 325-386 K. 
Analogous rate expressions are well known in enzyme catalysis [33]. Rate eqn. (16), far from equilibrium, yields expressions completely consistent with the observed dependencies of the initial rate of epimerization on the reaction conditions. It predicts in particular a maximal initial rate at a $\mathrm{pH}$ given by eqn. (14) and this $\mathrm{pH}$ is also characteristic for the maximum concentration of $\mathrm{SHMO}_{2} \mathrm{O}_{7}{ }^{-}$. Note that a reaction sequence for epimerization involving $\mathrm{SMo}_{2} \mathrm{O}_{7}{ }^{2-}$ or $\mathrm{SH}_{2} \mathrm{Mo}_{2} \mathrm{O}_{7}$ in the carbon skeleton rearrangement step would not lead to a rate equation in agreement with the observed $\mathrm{pH}$ dependency. A reaction sequence with another complexed molybdate, e.g. $\mathrm{SHMo}_{7} \mathrm{O}_{24}{ }^{5-}$, would lead to a rate equation analogous to eqn. (16), however. The only difference would be the physical meaning of the parameters and the substitution of the factor of $1 / 2$ by a factor of $1 / 7$.

If the temperature dependence of the protonation-deprotonation equilibria, eqns. (10) and (11), and of $K_{3,2,1, M} / K_{3,2,1, G}$ is neglected over the investigated range, rate eqn. (16) contains 9 independent parameters which are listed in Table 3. The available literature data on the standard enthalpies and entropies of formation of D-glucose and D-mannose [34] were not considered accurate enough to allow a reliable a priori calculation of the standard enthalpy and entropy of epimerization. Table 3 also shows the parameter estimates obtained by regression of the experimental data obtained in the batch reactor.

The maximum linear correlation occurs between $E_{\mathrm{a}}$ and both $\Delta S^{\circ}$ and $\Delta H_{\mathrm{r}}^{\mathrm{P}}$ and leads to a binary correlation coefficient of 0.88 . The ratio of the mean regression sum of squares to the mean residual sum of squares amounts to more than 100,000. The solid lines in Fig. 4 are obtained by integration of the continuity equation for D-glucose (2) with rate eqn. (16) and with the parameter estimates reported in Table 3 . The parity diagram shown in Fig. 9 shows the adequacy of the proposed rate equation. A further validation of rate eqn. (16) and the parameter estimates listed in Table 3 follows from

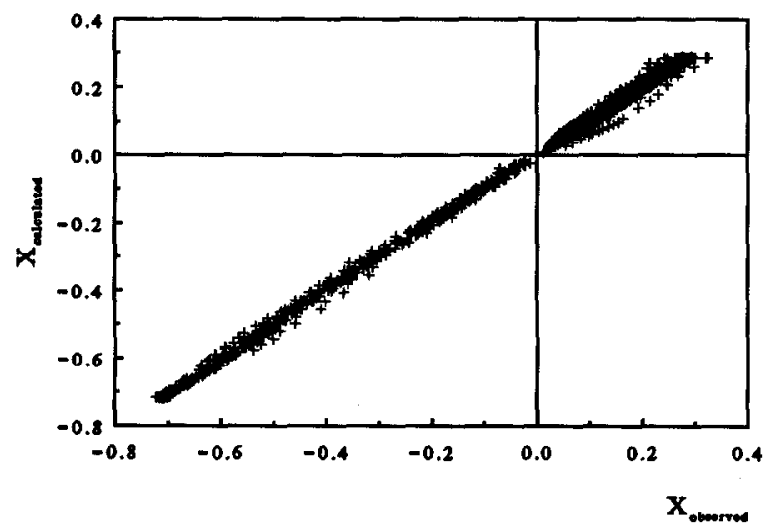

Fig. 9. Calculated vs. experimental conversions. The calculated values are obtained from integration of eqn. (2) with rate eqn. (16) and the parameter estimates from Table 3. Batch reactor. 


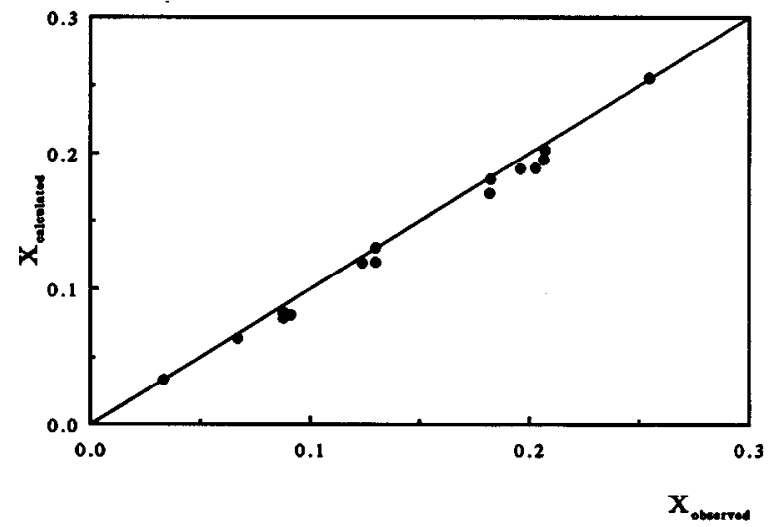

Fig. 10. Calculated vs. experimental conversions. The calculated values are obtained from eqn. (4) with rate eqn. (16) and the parameter estimates from Table 3. Continuous flow stirred tank reactor.

the comparison of the conversions calculated using eqn. (4) with the conversions observed in the continuous flow stirred tank reactor set-up, see Fig. 10. No regression was involved in this case. Finally, it should be mentioned that several other rate equations have been tested. Rate eqn. (16) gives by far the best description of the experimental observations.

\section{Equilibrium coefficient for epimerization}

The estimates for the standard reaction enthalpy and entropy reported in Table 3 lead to an equilibrium coefficient, $K$, of 0.35 and an equilibrium conversion, $X_{\mathrm{E}}$, of 0.26 at $348 \mathrm{~K}$ in reasonable agreement with the value given in the literature $[1,4,5,8,12]$. As the rate eqn. (16) describes the combined kinetics of epimerization, this holds also for the above values. It is possible to calculate the equilibrium coefficient of a reaction between combined components assuming internal equilibrium in each component [35]. Assuming equilibrium among the anomers of D-glucose and D-mannose and using the available thermodynamic literature data for each of them [34], a value is obtained for the equilibrium coefficient, $K$, in accordance with the value based on Table 3 . This is in line with the process observations mentioned earlier and validates the description of the epimerization based on combined kinetics.

\section{Rate coefficients for epimerization}

Based on Table 3, eqn. (5) and:

$k_{\mathrm{M}}=\frac{k_{\mathrm{G}} K_{3,2,1, \mathrm{G}}}{K K_{3,2,1, \mathrm{M}}}$

lead to values for the rate coefficient of the rate-determining step ranging from 0.01 to $0.5 \mathrm{~s}^{-1}$. The rate coefficient $k_{\mathrm{M}}$ is an order of magnitude smaller than $k_{\mathrm{G}}$, which explains the observations shown in Fig. 4. A typical initial 
TABLE 4

Standard activation enthalpies and entropies for the rate-determining step in the epimerization, $T_{\mathrm{m}}=358 \mathrm{~K}$

\begin{tabular}{lcc}
\hline & $\mathrm{G} \rightarrow \mathrm{M}$ & $\mathrm{M} \rightarrow \mathrm{G}$ \\
\hline$\Delta^{*} H^{\circ}\left(\mathrm{kJ} \mathrm{mol}^{-1}\right)$ & 123 & 129 \\
$\Delta^{*} S^{\circ}\left(\mathrm{J} \mathrm{mol}^{-1} \mathrm{~K}^{-1}\right)$ & 87 & 58 \\
\hline
\end{tabular}

turnover frequency of $\mathrm{D}$-glucose, i.e. the initial rate per mole of molybdenum, amounts to $0.3 \mathrm{~s}^{-1}$ at $348 \mathrm{~K}$.

The high value for the frequency factor, $A_{\mathrm{o}}$, can only be understood if degrees of freedom other than the translational one can help to overcome the activation barrier. Experimental evidence for the importance of activation in many degrees of freedom indeed mainly concerns unimolecular reactions [36]. Note that a rate equation based on a rate-determining step involving complexed heptamolybdate would have given raise to an even higher frequency factor.

The high frequency factor corresponds to high standard activation entropies, as indicated in Table 4, which shows the standard activation enthalpies and entropies for the rate-determining step based on Table 3 and:

$E_{\mathrm{a}}=\Delta^{*} H^{0}+R T$

$A_{\mathrm{o}}=\frac{e R T_{\mathrm{m}}}{N_{\mathrm{A}} h} \exp \left(\Delta^{*} S^{\circ} / R\right)$

The obtained standard activation entropies are approximately $40 \mathrm{~J} \mathrm{~mol}^{-1}$ $\mathrm{K}^{-1}$ higher than those reported by Sankovic et al. [12] at a $\mathrm{pH} \sim 5.5$, whose values are close to those listed in Table 4 . Hence, the higher $\mathrm{pH}$ seems to impose some steric requirements on the rate-determining step. It should be noted that, according to the data presented in Table $2, \mathrm{SMO}_{2} \mathrm{O}_{7}{ }^{2-}$ is the most abundant molybdate complex at a pH of 5.5. This suggests that an epimerization route involving $\mathrm{SMO}_{2} \mathrm{O}_{7}{ }^{2-}$ in the rate-determining step is slower than the route prevailing at the conditions investigated in the present work. Finally, it follows from Table 4 that the difference between $k_{\mathrm{G}}$ and $k_{\mathrm{M}}$ is caused by the standard activation entropy differences.

\section{Complexation and ionization coefficients}

Table 3 shows that the dimolybdate mannose complex is much more stable than the dimolybdate glucose complex. If the $K_{3,2,1, M} / K_{3,2,1, G}$ ratio is calculated from the titration experiments using the data in Table 2 and eqn. (9), a value of 7.1 is obtained. This corresponds to a complexation of Dglucose which is slightly more exothermic than that of D-mannose. The titration results indicated heats of complexation between 20 and $40 \mathrm{~kJ} \mathrm{~mol}^{-1}$.

A comparison of the values of the second ionization coefficients, $K_{2,5}$, reported in Tables 2 and 3 indicates an even smaller temperature dependency 
for the ionization steps. The above comparisons justify a posteriori the neglect of the mentioned temperature dependencies during the regression of the batch epimerization data.

The differences between the first and the second ionization coefficients are typical for weak acids with two ionizable protons.

\section{Discussion of the epimerization mechanism}

Two points are debated in the literature on the molybdate-catalysed epimerization: the nature of the catalytically active molybdate anion and the form in which the monosaccharide interacts with the former.

Sankovič and Sunjic $[11,12]$ suggested on the basis of a kinetic study that heptamolybdate anions are responsible for the epimerization through an oxo-allylic transition state involving $d-\pi$ interaction between the aldehyde form of the monosaccharide and the central Mo(VD) atom of the anion.

The aldehyde form had been proposed already by Hayes et al. $[9,10]$ as ligand, but with a dimolybdate as anion. It was proposed that the complexation with the molybdate anion induced a rehybridization so that in the transition state $\mathrm{C}-1$ and $\mathrm{C}-2$ have the same hybridization and form a tricentric bond with C-3. The configuration at C-3 is maintained, while bond breaking and bond formation occur on the same face of this carbon. The hypothesis of a dimolybdate as major anion was confirmed by Verchere and Chapelle [22] who excluded the aldehyde form of the monosaccharides on the basis of ${ }^{13} \mathrm{C}$ NMR, however.

The results reported here favor the hypothesis that a dimolybdate anion is catalytically active in the epimerization. No conclusions can be drawn concerning the form of the monosaccharide involved in the reactive complex, however. The degree of protonation of the reactive complex could be important in that respect. It can be envisaged that a double negative ion is formed from a pyranose form and $\mathrm{Mo}_{2} \mathrm{O}_{7}{ }^{2-}$, whereas upon protonation this complex could give an open chain form similar to the structure proposed by Hayes et al. $[9,10]$.

\section{Conclusions}

The kinetics of the molybdate-catalysed epimerization of D-glucose and D-mannose can be described adequately over a broad range of reaction conditions by a relatively simple rate equation. This rate equation is based on a reaction sequence with a monomolecular rate-determining step consisting of the carbon skeleton rearrangement. The latter is facilitated by the complexation of the reactant with a dimolybdate anion. The strength of the complexation is such that at the conditions investigated the presence of free molybdates can be neglected. The dependence of the epimerization rate on 
the $\mathrm{pH}$ can be accounted for by ionization equilibria of the complexes considered as weak acids with two ionizable protons.

\section{List of symbols}

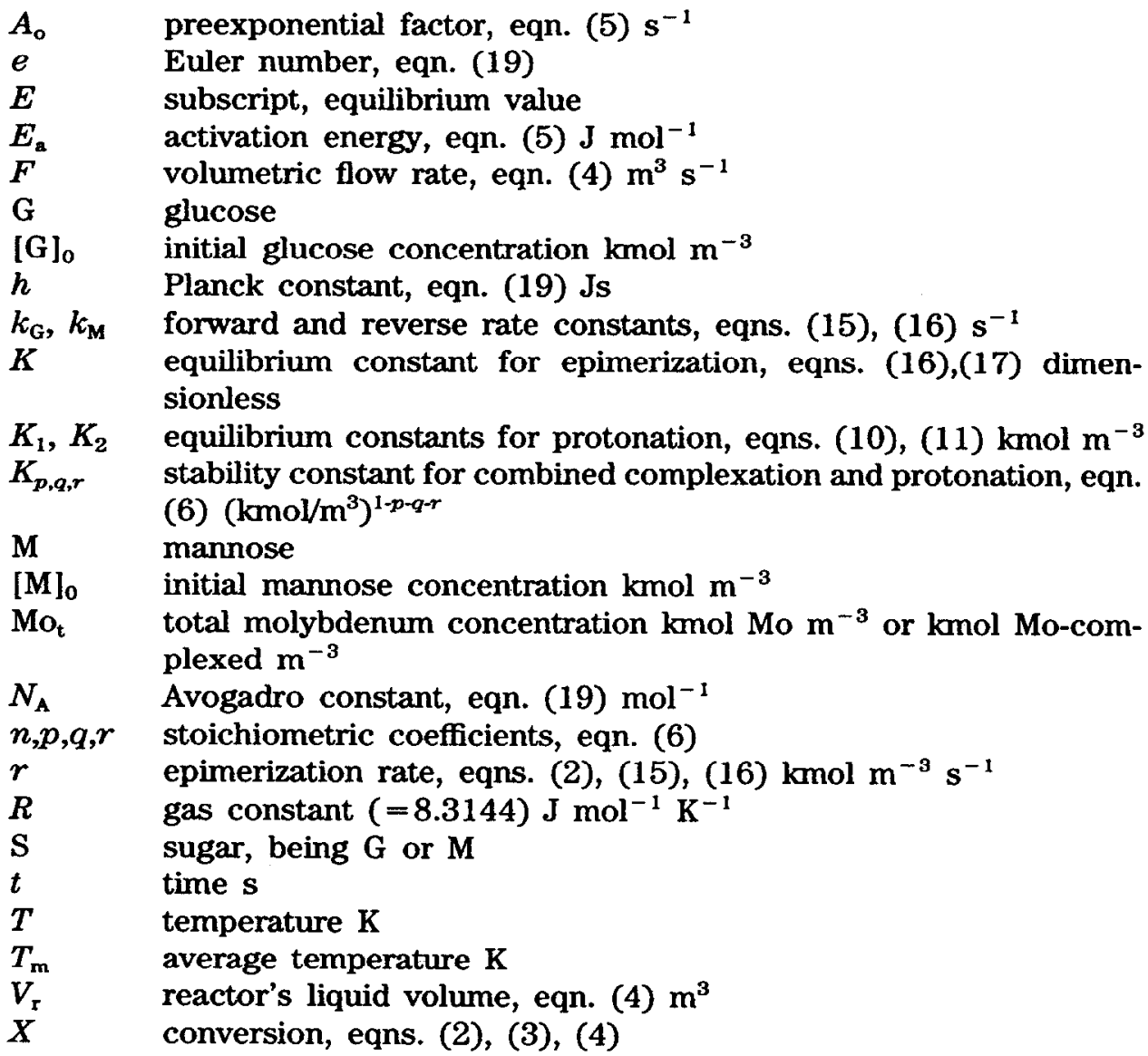

\section{References}

1 U.S. Pat. 4029878 (1977) to ICI; Brit. Pat. 1506534 (1978) to ICI; Ger. Pat. 2622316 (1976) to ICI.

2 V. Bilik, Chem. Zvesti, 26 (1972) 76, 183, 187, 372.

3 V. Bilik, L. Petrus and V. Farkas, Chem. Zvesti, 29 (1975) 690.

4 V. Bilik, L. Petrus and J. Zemek, Chem. Zvesti, 32 (1978) 242.

5 V. Bilik and K. Babor, Chem. Zvesti, 37 (1983) 6, 791.

6 V. Bilik, W. Voelter and E. Bayer, Angew. Chem. Int. Ed. Engl, 10 (1971) 909.

7 V. Bilik, L. Petrus, M. Miskova and V. Sutoris, Chem. Zvesti, 33 (1979) 114.

8 V. Bilik and K. Knezek, Chem. Papers, 42 (1988) 34.

9 M. L. Hayes, N. J. Pennings, A. S. Serianni and R. Barker, J. Am. Chem. Soc., 104 (1982) 6764. 
10 E. L. Clark, M. L. Hayes and R. Barker, Carbohydr. Res., 153 (1986) 263.

11 B. Klaiē, Z. Raza, M. Sankovič and V. Sunjič, Helv. Chim. Acta, 70 (1987) 59.

12 M. Sankovic̄, S. Emini, S. Rusman and V. Sunjič, J. Mol Catal., 61 (1990) 247.

13 G. F. Froment and L. H. Hosten, in J. K. Anderson and M. Boudart (eds.), Catalysis, Science and Technology, Springer Verlag, Berlin, 1981, Chapt. 3.

14 N. R. Draper and H. Smith, Applied Regression Analysis, Wiley, New York, 1966.

15 J. J. Cruywagen, Inorg. Chem., 19 (1980) 552.

16 J. Aveston, E. W. Anacker and J. S. Johnson, Inorg. Chem., 3 (1964) 735.

17 D. S. Honig and K. Kustin, Inorg. Chem., 11 (1972) 65.

18 G. Schwarzenbach and J. Meier, J. Inorg. Nuch. Chem., 8 (1958) 302.

19 J. Kula, Anal. Chem, 38 (1966) 1382.

20 K. H. Tytko, G. Baethe and J. J. Gruywagen, Inorg. Chem., 24 (1985) 3132.

21 K. H. Tytko, G. Baethe, E. R. Hischfeld, K. Mehmke and D. Stellhorn, Z. Anorg. Allg. Chem., 503 (1983) 43.

22 J. F. Verchere and S. Chapelle, Polyhedrom, 8 (1989) 333.

23 M. Mikesova and M. Bartusek, Czech. Chem. Commren, 43 (1978) 1867,

24 B. Hedman, Acta Crystallogr., Sect. B, B33 (1977) 3077.

25 H. J. F. Angus and H. Weigel, J. Chem. Soc., (1964) 4000.

26 W. Voelter, G. Kuhfittig, G. Schneider and E. Bayer, Justus Liebigs Ann. Chem., 734 (1970) 126.

27 W. Voelter, E. Bayer, R. Records, E. Bunnenberg and C. Djerassi, Justus Liebigs Ann. Chem., 718 (1968) 238.

28 E. Bayer and W. Voelter, Ann. Chem., 696 (1966) 194.

29 E. J. Bourne, D. H. Hutson and H. Weigel, J. Chem. Soc., 35 (1961) 54.

30 J. Alfoldi, V. Bilik and L. Petrus, Collect. Czech. Chem. Commun., 45 (1980) 123.

31 J. Alfoldi, L. Petrus and V. Bilik, Collect. Czech. Chem. Commun., 43 (1978) 1476.

32 W. Pigman and H. S. Isbell, Adv. Carbohydr. Chem., 23 (1968) 11; 24 (1969) 13.

33 I. M. Campbell, Catalysis at Surfaces, Chapman and Hall, London, New York, 1988.

34 S. J. Angyal, Angew. Chem. Int. Ed. Engh, 8 (1969) 157.

35 R. D. Alberty, Ind. Eng. Chem. Fundam., 22 (1983) 318.

36 R. C. Wayne, in C. H. Bamford (ed.), Comprehensive Chemical Kinetics, Elsevier, Amsterdam, 1969, p. 189. 